\title{
Creative profile of IT specialists - an adaptation of Creative Behaviours Questionnaire for remote use with Software Development Specialists
}

\author{
Józefacka, N. ${ }^{1,2}$, Zioło, M. $^{2}$, Majchrowicz ${ }^{2}$, B, Jaros, J. $^{2}$, Zaremba, D. ${ }^{2}$ \\ ${ }^{1}$ Pedagogical University of Kraków, Kraków, Poland \\ ${ }^{2}$ Talent Alpha Sp.z o.o, Kraków, Poland \\ E-mail: dominika.zaremba@talent-alpha.com
}

\begin{abstract}
Improvisation, innovation and adaptation, all of which are in close relationship with creativity, are very important throughout the whole process of the software development cycle and for every IT role involved in it. This tendency is very well visible especially among representatives of Agile practitioners, a group that has been rapidly growing in the last decades. In this paper we adapt pen-and-paper Creative Behaviours Questionnaire for remote, digital testing among specialists employed in the area of software development and IT. In the adaptation process the psychometric properties of the scale were confirmed, and the PCA and CFA analyses were conducted on the revised version of the scale. The CFA analyses, conducted for the first time on this questionnaire, revealed poor fit to the model for the whole scale, however a good fit was confirmed for the two subscales separately.
\end{abstract}

Keywords: creativity, information technology, software development, remote measurement

\section{Introduction}

Over two decades ago Winograd (2000) has indicated that we should be paying more attention to human factors in software engineering, especially to creativity. Since then, this trait together with other personality characteristics gained more interest from researchers in the field and has been discussed as one of the most important traits of high performing knowledge-workers, including IT specialists (Wynekoop, Walz 2000). According to the growing body of papers, both by software engineering practitioners and researchers, creativity has been indicated as a key success factor that is beneficial in terms of cost, quality and satisfaction (Maiden, Jones, Karlsen, Neil, Zachos and Milne, 2010; Graziotin et al., 2013). Growing importance of this trait can be attributed to the increasing pressure to automate growing part of work and write shorter and well-optimized code. Faced by such challenges, software developers need to employ unusual strategies and innovate the solution iteratively. Besides that, an optimal representation of the concepts and processes in a programming language, thorough software testing or highly usable design solutions demand a lot of creative input from the employees in the IT industry (Mich, Anesi and Berry, 2004; Graziotin et al., 2013).

\subsection{Creativity in Software Development}

Creativity related traits such as improvisation, innovation and adaptation, are very important throughout the whole process of software development cycle and for every role IT role involved in it. This tendency is very well visible especially among representatives of Agile practitioners, a group that has been rapidly growing in the last decades. This group often claims that, in contrast to more classic IT methodologies (e.g. waterfall), they heavily rely on the creative talent of the people to improvise solutions for complex software development problems (Cockburn \& Highsmith, 2001; de la Barra, et 
al., 2013). It can be observed in the management phase of software development, when the project manager is encouraged to adopt agile methods in addressing development process challenges and to foster creativity (Sutling, Mansor and Widyarto, 2014). As well as on the stage of software testing e.g. exploratory testing has been identified to depend on human cognition and supports creativity (Shoaib, Nadeem, and Akbar, 2009). Moreover, researches have also investigated creativity in requirement engineering, with emphasis on framing requirement as a creative solving process (Maiden et, al., 2010) and in software design (Akin, 1990; Ball, Onarheim \& Christensen, 2010; Díaz et al., 2014). Requirement engineering encourages the adoption of creative techniques as an important tool for user's requirement content clarity and implementation (Saha, Selvi, Buyukcan and Mohymen, 2012; Maiden, Jones, Karlsen, Neil, Zachos and Milne, 2010; Crawford, Barra, Sot and Monfroy, 2012; Nguyen and Shanks, 2008; Lemos, Alves, Duboc and Rodrigues, 2012). Due to those facts, we can see that the creative aspect of human nature is receiving more and more attention from tech employers during the selection and recruitment process. In consequence, a reliable measurement of creativity as a trait is becoming an increasing concern of hiring managers.

\subsection{Theories of creativity}

Taking into account the specific requirements of the tech industry, not all creativity models seem to be applicable to the same extent in this area. Plenty of them focus mostly on defining the qualities of the creative product, whilst in this specific context it seems that it would be more beneficial to focus on the creative process instead. One of the earliest definitions of this construct as the ability to innovate and invent solutions that hold to the multiple requirements and limitations was proposed by Kirton (1976). It may prove more useful than other models of creativity in the discussed context of IT workers as it fits to the perspective described above. Adaptation - Innovation continuum described by Kirton relates to the behaviours expressed in a vocational environment that demands the "creativity harnessed in the reins of business requirements".

The adaptation-innovation continuum is assumed to be a dimension of creative style, that is, stable within time as well as across situations and has links to certain personality traits (Kirton, 1999). Both innovators and adaptors are equally creative, the only difference is how they express their creativity. Adaptors operate within a framework of systems and are associated with the sufficiency of originality, efficiency and rule-group conformity whereas innovators break away from the existing framework of systems and are associated with high-interest levels in terms of originality of ideas, less concern for efficiency and rule-group conformity. Adaptors prefer to create change by improving on the existing structure and favour staying in groups (Kirton, 1994). In addition, they maintain cohesion by following the accepted ways and prefer to solve problems in a disciplined, methodical and predictable manner. On the other hand, innovators often come up with many new and practical ideas and are risk-oriented (Kirton, 1994). They prefer to stay as individuals and create change by altering the existing paradigm (Kirton, 1994).

Based on this model proposed by Kirton (1994), Foxall and Bhate (1991) established an image of adaptors as people who tend to be well-organized, detail-oriented and conformist. On the other hand, they see innovators as those who tend to question the status quo and think outside the box. According to existing research regarding people working in the IT industry, software developers who are closer to the innovators' side of the described spectrum are generally more satisfied with their job and achieve slightly higher performance (Galivan, 2003).

From the perspective of the componential model proposed by Amabile's creativity is described as a construct that precedes innovation (1996). The author states that a person's creative potential is dependent on three main factors: their domain skills, creativity relevant skills and intrinsic task motivation. First factor relates to expertise in the relevant domain or domains. Among creativity relevant processes Amabile lists e.g. concentration, dedication, perseverance, risk-taking and need for novelty. In the models view, thanks to high intrinsic motivation creative people tend to take up new challenges for sole interest and satisfaction of overcoming them. According to the componential model people's level of creativity is an outcome of interaction between those 3 factors (Amabile \& Pillemer, 2012).

According to a theory of creativity proposed by Popek (2000, etc.), which is similar to the described above, well-established Amabile's theory (1983, 1996), this construct can be identified on two distinctive levels: cognitive (heuristic thinking) and behavioural (nonconformism). In the view of the author's model (2000, 2001), creativity and/or creative attitude can be defined as "an active approach towards the world and life, manifesting itself in the need of cognition and conscious processing of environment and one's self'. Furthermore, according to Popek's theory, creativity is a product of, not only cognitive predispositions of a given person but also their characterological qualities. According to the author various configurations of persons, broadly defined, cognitive predispositions can lead to adopting a different way of thinking and processing information. It can be described on a continuum between algorithmic and 
heuristic thinking styles. The first one is characterized by logical understanding and analysis, convergent thinking, reproductiveness, attention for details and ability to discover underlying patterns. On the other end of the continuum, the author placed a heuristic reasoning style that is characteristic for creative people and leads to cognitive flexibility and unconventionality as well as a bigger tendency towards thinking out of the box and ability to find novel solutions to the encountered problems.

The second building block - characterological qualities includes a set of properties belonging to the structure of the personality ensuring active realization of potential cognitive abilities of an individual. These properties lead to various behavioral profiles that can be described on a continuum between nonconformism and conformism. The first one is defined by the following features: independence, adaptive flexibility, originality, assertiveness, domination, self-organization, spontaneity, expressiveness and openness. (Popek, 2000). The opposite profile is expressed through preference towards stable rules and environment, predictability, adaptive stiffness and compliance.

In the view of the described model the most creative people are often nonconformists that tend to exhibit a range of heuristic behaviours. To measure these tendencies Popek has created Creative Behaviour Questionnaire that had some revisions throughout the years and the newest one was proposed by Bernacka (2009).

\subsection{Exploration of IT specialists personality profiles}

Current research was also perceived as an opportunity to investigate the possibility of variance in personality profiles between specialists of different IT roles. The potential occurrence of such differences was already discussed and described by various authors (e.g. Capretz, Varona \& Raza, 2015; Cruz, da Silva \& Capretz, 2015). For example Kanij, Merkel, \& Grundy (2015) have identified significant differences between the group of software testers/QA engineers and the rest of the software development workforce. According to their research software testers exhibit higher levels of conscientiousness than their colleagues but don't differ significantly on other personality traits. In another study conducted by Martínez et al (2010) authors have identified more differences, such as higher level of agreeableness among developers whilst lower for analysts as well as higher extraversion among architects and software testers.

However, it is very important to note that most of the previous papers on that topic were written in reference to the MBTI personality framework (e.g. Capretz \& Ahmed, 2010). This is problematic as the MBTI model is often criticized (e.g. Stein \& Swan, 2019) and in consequence it is considered as unreliable by the scientific community. Because of that, research based on a more universally used model like the well-studied Big Five would be beneficial in two ways. Firstly, it will provide data of higher quality for scientists. Secondly it will serve as a source of more trustworthy insights for the IT management bodies, not only allowing them to identify potential leaders in their teams but also helping them to plan career paths with specialists. This opportunity for verification of personality patterns based on MBTI framework studies was an additional motivation for investigation conducted in current research.

In order to gather data that will be most relevant to the analyzed professional work context we have decided to use Business Inventory of Personality (BIP) in our study. As it's based on the Big Five personality model it should also allow us to compare our data with results of the studies conducted previously by other authors.

\subsection{Exploration of leader roles personality profiles}

The possibility to define qualities that can be used to distinguish natural leaders from their colleagues was in the area of interest of organizational psychologists for a long time (Zaccaro et al., 2004). Even though this topic was over the years dominated by the situational rather than dispositional approach, the relation between personality and leadership competences still remains of valid interest and can lead to valuable discoveries (Hogan \& Judge, 2012).

Judge, Bono, Ilies \& Gerhardt (2002) conducted a meta-analysis of the leader trait approach based on the Big Five model and provided evidence of existing personality patterns among leaders. According to their research, four out of five personality factors were linked with leadership competences: extraversion, emotional stability, conscientiousness and openness to experience. They found multiple correlations of this model with leader emergence $(r=.58)$ and leadership effectiveness ( $r$ $=.39$ ) Based on a more recent metaanalysis of studies on leadership emergence Ensari et al (2010) have suggested that individuals with high extraversion, social skills, intelligence and authoritarian personality have the highest chance of emerging as a leader among their colleagues. In another meta-analysis (Cruz, da Silva \& Capretz, 2015 ) in which the authors focused on personality studies in the IT industry, a scarcity of evidence was pointed out.

Based on previous research described in this section we hypothesize that we will observe significant differences of personality traits between IT roles, especially between leadership/managerial roles and other, non-managerial roles. We expect to observe intergroup differences in 
nonconformism, conscientiousness and assertiveness traits.

Furthermore, we also hypothesize that specialists who occupy leadership-oriented roles will present a consistent personality profile that will differ significantly from their colleagues on scales measuring traits like nonconformism, leadership and power motivation as well as conscientiousness, emotional stability and self-confidence.

\section{Method}

\subsection{Participants}

Participants were recruited through contact with representatives of small and medium-sized software companies in Poland, who are the partners and clients of company Talent Alpha. Active employment in the area of software development, fluency in Polish and English and ownership of a mobile device with Android or iOS system were inclusion criteria for the participants. Due to the substantial differences in skill profiles of people working in different areas of software development, we decided to balance the group sizes of distinctive and popular IT roles: Back-end developers, Front-end developers, Full-Stack Developers, Leaders/Managers and Designers (UX/UI). Participants were informed about the need to download and install an application on their mobile device and the Epsilon software on their PC. They were also informed that the employer would not get access to their specific answers and would not receive individual results, but would be provided with an aggregated, anonymized group report.

\subsection{Tools}

A proprietary research application, TalentLab App, was developed for the purposes of data collection in this study. Participants voluntarily downloaded and installed the app. All measurements were administered on the participant's own mobile devices. TalentLab App included several psychometric tools:

Creative Behaviors Questionnaire (CBQ, polish version: Kwestionariusz Twórczego Zachowania KANH III) is a self-report questionnaire that measures expressions of creative behaviours. According to Popek's theory $(2000,2001)$, creativity is a product of both cognitive as well as characterological predisposition, so the questionnaire measures cognitive and personality-related creative attitudes. CBQ consists of 26 items in two equinumerous subscales (algorithmic heuristic thinking and conformism - nonconformism). The result can be interpreted separately for each scale and also for a whole scale on the dimension of creative-reproductive attitude.

For measuring job satisfaction we used the Job Satisfaction Index (Schriesheim, Tsui 1980, JSI). This 6-item questionnaire assesses six areas of satisfaction, including the nature of the job, supervision, co-workers, remuneration, promotion opportunities, and the job in general.

We used three different measures to estimate individual work performance. All questionnaires were presented sequentially in a single "My Performance" form. We used two subscales from Individual Work Performance Questionnaire (IWPQ, Koopmans, 2014) - Task Performance and Contextual Performance scales. Task Performance scale (5 items) is a measure of the proficiency with which employees perform the core technical tasks in their job (Campbell, 1990). Contextual performance scale ( 8 items) measures behaviours that support the organizational, social and psychological environment in which the technical core must function, for example, volunteering, persisting and helping (Koopmans, 2014) .

To measure general work performance we incorporated 7-item Williams Shortened Questionnaire (Williams, Anderson, 1991) and a question "How would your employer probably rate your work performance?", (Robinson, 1996). In total, the My Performance form consisted of 21 items.

Besides above mentioned questionnaires the TalentLab app included a 10-minute-long gamified cognitive task, Dot Memory Game, that was a tool for measuring visuospatial working memory. Completion of this task was not the subject of this study, however, the participants usually played the game prior to or just after completing the questionnaires.

For purposes of validity testing, we used the Business Inventory of Personality (BIP) by Hossiep and Paschen (2003; Polish adaptation: Bochumski Inwentarz Osobowościowych Wyznaczników Pracy by Psychological Test Laboratory Polish Psychological Association). BIP is a self-report questionnaire that measures 14 personality characteristics relevant to vocational functioning. The questionnaire consists of 220 questions answered on a 6-point Likert scale. Polish adaptation of the questionnaire is available on Epsilon Platform, which allows remote testing. Epsilon software was developed by the Psychological Test Laboratory of the Polish Psychological Association. The software has to be downloaded and installed on a personal computer and could be deleted by the participant after measurement completion

\subsection{Procedure}


All communication with study participants, including information and consent form distribution, links to software downloads and technical support was held remotely via email. For each company, a set of informational materials was presented by the researchers to the company owners and managers and then distributed to employees by company managers. Participants were informed about the possibility to take part in a study by their managers and applied via a contact form, leaving their personal information and email address.

Prior to the data collection phase participants received read-only Informed Consent Form by email and later provided informed consent via a form in the app. With the beginning of the data collection phase, all participants received an email with a link to download the TalentLab app and invitation to complete all of the measurements inside it. In the following email (distributed around two weeks later) participants were instructed how to download Epsilon Software and conduct the BIP questionnaire. Links and unique individual access codes to the questionnaire were distributed to individual emails of specialists.

After completing the questionnaire, participants were sent individual, automatically generated reports from the measurement. There were no limitations of when the participant should complete the measurements inside the app or on the Epsilon platform, and some of them did not complete some or any measurements. The researcher announced the upcoming end of data collection phase 2 weeks prior to the end of the data collection. In the meantime, participants have received other email communications regarding technical support and use of another external web platform for cognitive assessments that were not the subjects of this study.

\section{Results}

For the purpose of statistical analysis IBM SPSS Statistics 25 and AMOS packages were used for basic descriptive statistics along with the Kolmogorov-Smirnow tests, exploratory factor analysis, confirmatory factor analysis, Student's t-test for independent groups, Mann-Whitney U test and Pearson's r correlation analysis. The level of statistical significance in this chapter is $\alpha=0.05$.

\subsection{Basic \& Descriptive Statistics}

We have obtained data from 185 participants (43 female, 200 male) working in software development teams. Almost $75 \%$ of participants were male, which reflects the distribution of gender affiliation in the IT sector. There were more people on regular (100) and senior specialist (109) positions than inexperienced employees (33). The table 1. describes the demographic characteristics of the sample.

\begin{tabular}{|l|c|c|c|c|}
\hline Seniority & $\mathbf{N}$ & \% woman & \% man & Age range \\
\hline Junior & 33 & $36,4 \%$ & $63,6 \%$ & $21-35$ \\
\hline Regular & 100 & $22,8 \%$ & $77,2 \%$ & $21-41$ \\
\hline Senior & 109 & $11,9 \%$ & $88,1 \%$ & $25-41$ \\
\hline
\end{tabular}

Table 1. Study sample demographic information.

We investigated the normality of scores distribution for all quantitative variables. For this purpose, basic descriptive statistics were calculated together with the Kolmogorov-Smirnow test examining the normality of the distribution. The results of the analysis are presented in Table 2.

M Me SD Sk. Kurt. Min. Max. D $\quad$ p

\section{CBQ III}

\begin{tabular}{lllllllllll} 
Conformism - Nonconformism & 36,59 & 37,00 & 5,67 & $-0,29$ & $-0,51$ & 21 & 49 & 0,09 & 0,101 \\
Algorithmic - Heuristic & 35,13 & 35,00 & 5,56 & $-0,07$ & $-0,03$ & 19 & 48 & 0,08 & 0,187 \\
\hline
\end{tabular}




\begin{tabular}{|c|c|c|c|c|c|c|c|c|c|}
\hline Job Satisfaction & 16,71 & 22,00 & 11,91 & $-0,58$ & $-1,46$ & 0 & 30 & 0,14 & 0,000 \\
\hline Task Performance & 19,43 & 20,00 & 2,76 & $-0,64$ & 0,71 & 9 & 25 & 0,11 & 0,013 \\
\hline Contextual Performance & 31,86 & 33,00 & 4,70 & $-0,45$ & 0,00 & 17 & 40 & 0,12 & 0,005 \\
\hline General Performance & 16,86 & 24,00 & 11,92 & $-0,66$ & $-1,46$ & 0 & 35 & 0,11 & 0,010 \\
\hline Single Question Performance & 4,24 & 4,00 & 0,62 & $-0,20$ & $-0,56$ & 3 & 5 & 0,34 & 0,000 \\
\hline \multicolumn{10}{|l|}{ BIP } \\
\hline Achievement Motivation & 60,58 & 60,00 & 9,02 & $-0,02$ & 0,20 & 32 & 81 & 0,08 & 0,170 \\
\hline Power Motivation & 48,89 & 49,00 & 7,36 & 0,24 & $-0,22$ & 32 & 68 & 0,09 & 0,141 \\
\hline Leadership Motivation & 51,95 & 50,00 & 13,63 & 0,40 & $-0,47$ & 25 & 90 & 0,09 & 0,105 \\
\hline Conscientiousness & 57,52 & 58,00 & 11,07 & $-0,45$ & 0,18 & 24 & 80 & 0,08 & 0,200 \\
\hline Flexibility & 46,15 & 45,00 & 10,28 & 0,58 & 0,65 & 22 & 80 & 0,07 & $.0,200$ \\
\hline Action Orientation & 56,52 & 58,00 & 11,91 & $-0,31$ & $-0,70$ & 31 & 80 & 0,09 & 0,067 \\
\hline Social Sensitivity & 49,39 & 49,00 & 8,36 & $-0,12$ & $-0,80$ & 32 & 67 & 0,10 & 0,026 \\
\hline Openness to Contact & 62,21 & 63,00 & 13,34 & $-0,13$ & $-0,72$ & 35 & 90 & 0,08 & 0,200 \\
\hline Sociability & 62,54 & 63,00 & 9,48 & $-0,71$ & 0,31 & 37 & 81 & 0,10 & 0,021 \\
\hline Team Orientation & 48,32 & 49,00 & 9,92 & $-0,53$ & $-0,04$ & 16 & 67 & 0,09 & 0,048 \\
\hline Assertiveness & 48,81 & 50,00 & 8,36 & $-0,03$ & $-0,26$ & 27 & 68 & 0,07 & 0,200 \\
\hline Emotional Stability & 57,68 & 58,00 & 13,83 & $-0,40$ & $-0,51$ & 23 & 82 & 0,07 & 0,200 \\
\hline Work under pressure & 48,18 & 48,00 & 10,95 & 0,08 & $-0,40$ & 24 & 72 & 0,07 & 0,200 \\
\hline Self-confidence & 60,92 & 60,00 & 12,52 & 0,18 & $-0,44$ & 32 & 94 & 0,07 & 0,200 \\
\hline
\end{tabular}

Table 2. Basic descriptive statistics of the studied variables together with the Kolmogorov-Smirnow test.

The results of the Kolmogorov-Smirnov indicate that for some variables distributions deviate from a normal distribution. However, it should be noted that the skewness of the distribution for most variables does not exceed the conventional absolute value equal to 1 , which means that their distribution is slightly asymmetric.

\subsection{CBQ III Questionnaire Adaptation}

This part of analysis focuses on CBQ III questionnaire adaptation.

\subsubsection{CBQ III Questionnaire.}

CBQ III measures expressions of creative behaviours and consists of two subscales: conformism nonconformism, (C-N) which measures the personality-related expression of creativity, and the algorithmic - heuristic scale (A-H), which measures manifestations of creativity in the cognitive processes. 
Each subscale measures 13 properties of a continuous nature. The questionnaire consists of 26 items.

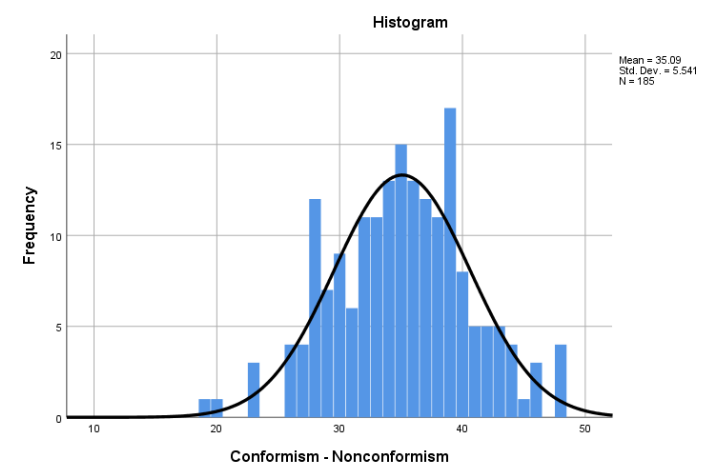

Figure 1. CBQ Conformism - Nonconformism Scale score distribution for the study sample.

\subsubsection{Reliability analysis.}

In CBQ III, the results can be interpreted both for the full scale and independently for each subscale. Cronbach's alpha reliability test values calculated for the modified version of CBQ III equaled 0.63 for the Conformism-Nonconformism scale, 0.66 for the Algorithmic-Heuristic scale and 0.77 for the full scale. In the original studies, the Cronbach's alpha statistic of the modified version of CBQ III was 0.69 for the $\mathrm{C}-\mathrm{N}$ scale, and 0.65 for the $\mathrm{A}-\mathrm{H}$ scale, respectively. Despite the limited sample size, the reliability of CBQ III in a study with IT specialists is at a similar level to that of the authors of the modified version. We have also calculated reliability scores separately for 3 seniority levels (Table 3).

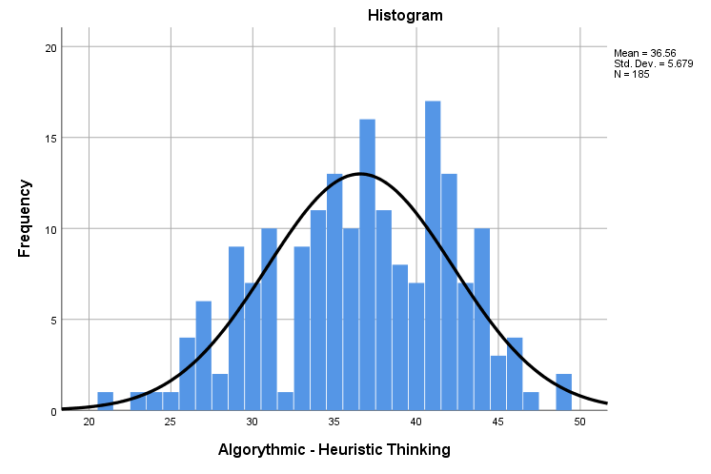

Figure 2. CBQ Algorithmic - Heuristic thinking Scale score distribution for the study sample.

\begin{tabular}{|l|l|l|}
\hline & $C-N$ & $H-A$ \\
\hline Junior & 0,72 & 0,47 \\
\hline Regular & 0,56 & 0,66 \\
\hline Senior & 0,65 & 0,70 \\
\hline
\end{tabular}

Table 3. Cronbach's Alpha statistics for both CBQ scales in each seniority scale.

\subsubsection{Exploratory data analysis.}

In order to determine the internal structure of the $\mathrm{C}-\mathrm{N}$ and A-H scales, an exploratory factor analysis using the principal components method was performed. The factors were extracted using the Catell method, based on the scree plot (Figures 3 and 4). In both cases, the last substantial drop in the magnitude of eigenvalues is observed around value 4 . Tables 4 and 5 show the factor loadings of individual items and the percentage of explained variance. 


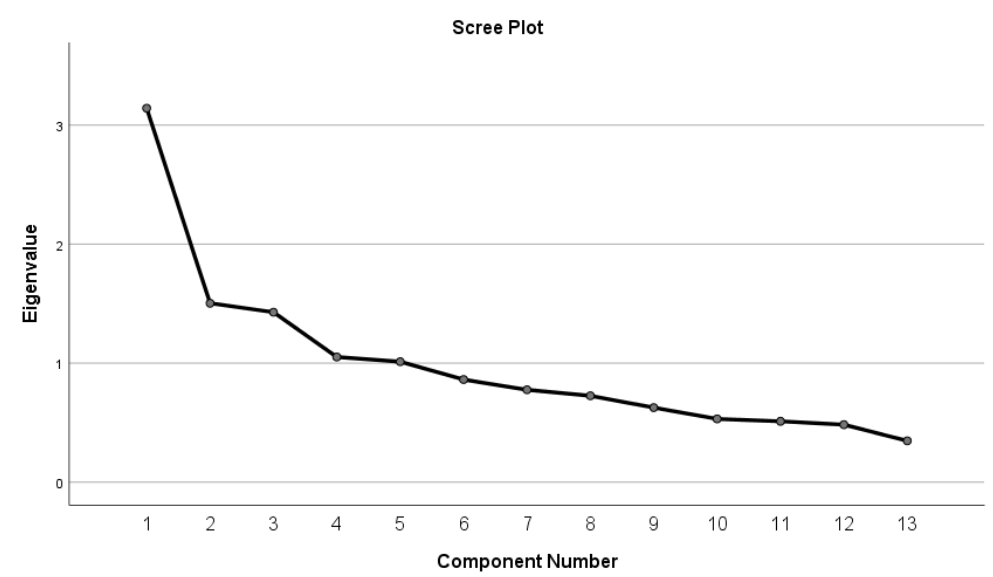

Figure 3. Scree plot for factors in CBQ Algorithmic - Heuristic thinking Scale.

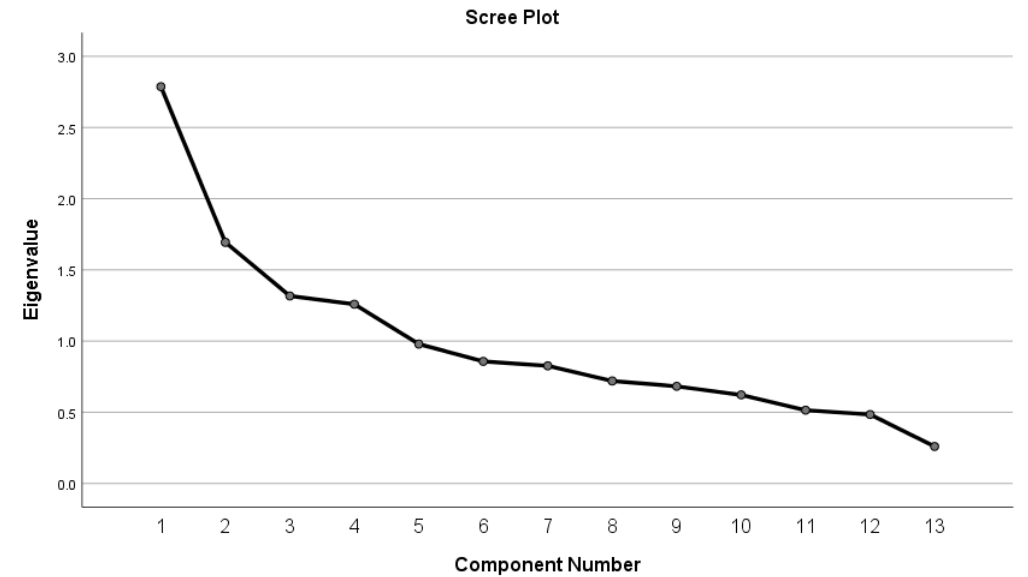

Figure 4. Scree plot for factors in CBQ Conformism- Nonconformism Scale.

Similarly, as in the analyses conducted by the authors of the revised version, 4 dimensions were observed for the C-N scale. However, factors identified in our study do not map precisely onto factors in the original research. In tables 8 and 9 we list the items belonging to each identified factor and propose names for the respective factors.

\begin{tabular}{ccccccc}
\hline & \multicolumn{3}{c}{ Initial Eigenvalues } & \multicolumn{3}{c}{ Rotation sums of squared loadings } \\
\cline { 2 - 5 } Factor & Total & $\begin{array}{c}\text { \% of } \\
\text { variance }\end{array}$ & $\begin{array}{c}\text { Cumulati } \\
\text { ve \% }\end{array}$ & Total & $\begin{array}{c}\text { \% of } \\
\text { variance }\end{array}$ & Cumulative \% \\
\hline 1 & 2.787 & 21.438 & 21.438 & 2.290 & 17.614 & 17.614 \\
2 & 1.693 & 13.026 & 34.465 & 1.670 & 12.849 & 30.463 \\
3 & 1.317 & 10.128 & 44.593 & 1.572 & 12.091 & 42.554 \\
4 & 1.259 & 9.685 & 54.278 & 1.524 & 11.724 & 54.278 \\
5 & .979 & 7.528 & 61.806 & & & \\
6 & .857 & 6.594 & 68.400 & & &
\end{tabular}




\begin{tabular}{llll}
7 & .826 & 6.355 & 74.755 \\
8 & .720 & 5.536 & 80.291 \\
9 & .682 & 5.246 & 85.537 \\
10 & .622 & 4.783 & 90.320 \\
11 & .514 & 3.957 & 94.277 \\
12 & .484 & 3.725 & 98.002 \\
13 & .260 & 1.998 & 100.000 \\
\hline
\end{tabular}

Table 4. Conformism - Nonconformism scale exploratory analysis.

\begin{tabular}{|c|c|c|c|c|c|c|}
\hline \multirow[b]{2}{*}{ Factor } & \multicolumn{3}{|c|}{ Initial Eigenvalues } & \multicolumn{3}{|c|}{ Rotation sums of squared loadings } \\
\hline & Total & $\begin{array}{c}\% \text { of } \\
\text { variance }\end{array}$ & Cumulative \% & Total & $\begin{array}{c}\% \text { of } \\
\text { variance }\end{array}$ & Cumulative \% \\
\hline 1 & 3.142 & 24.169 & 24.169 & 2.386 & 18.354 & 18.354 \\
\hline 2 & 1.503 & 11.563 & 35.732 & 2.146 & 16.504 & 34.858 \\
\hline 3 & 1.428 & 10.986 & 46.718 & 1.450 & 11.153 & 46.012 \\
\hline 4 & 1.051 & 8.087 & 54.805 & 1.143 & 8.794 & 54.805 \\
\hline 5 & 1.012 & 7.786 & 62.591 & & & \\
\hline 6 & .862 & 6.632 & 69.223 & & & \\
\hline 7 & .776 & 5.969 & 75.192 & & & \\
\hline 8 & .726 & 5.583 & 80.775 & & & \\
\hline 9 & .627 & 4.820 & 85.595 & & & \\
\hline 10 & .531 & 4.086 & 89.681 & & & \\
\hline 11 & .511 & 3.933 & 93.613 & & & \\
\hline 12 & .483 & 3.715 & 97.328 & & & \\
\hline 13 & .347 & 2.672 & 100.000 & & & \\
\hline
\end{tabular}

Table 5. Algorithmic - Heuristic scale exploratory analysis. 


\begin{tabular}{lcccc}
\hline & 1 & 2 & 3 & 4 \\
\cline { 1 - 1 } K2 & 0,62 & 0,39 & & \\
K4 & 0,87 & & & \\
K5 & & & $-0,54$ & 0,32 \\
K7 & & 0,31 & 0,66 & \\
K9 & & & 0,60 & \\
K12 & & & & 0,70 \\
K16 & 0,36 & & & 0,32 \\
K18 & 0,31 & 0,62 & & \\
K20 & & 0,76 & & 0,31 \\
K22 & 0,86 & & & 0,75 \\
K24R & & 0,52 & & \\
K25 & & & 0,66 & \\
K26 & & & & \\
\hline
\end{tabular}

Table 6. Rotated component matrix for C-N scale.

\begin{tabular}{ccccc}
\hline & 1 & 2 & 3 & 4 \\
\hline K1 & & & & 0,866 \\
K3 & 0,741 & & 0,594 & 0,306 \\
K6 & 0,304 & & & \\
K8 & 0,689 & & & \\
K10 & & 0,677 & & $-0,341$ \\
K11 & & 0,800 & & 0,344 \\
K13 & 0,374 & 0,515 & & \\
K14 & 0,589 & & & \\
K15R & & & 0,570 & \\
K17 & & 0,655 & & \\
K19 & 0,363 & & $-0,688$ & \\
K21 & 0,686 & & & \\
K23 & 0,379 & 0,525 & & \\
\hline
\end{tabular}

Table 7. Rotated component matrix for A-H scale. 
Factor 1. Initiative

\begin{tabular}{lccl}
\hline Conformism & Item number & Factor load & Nonconformism \\
\hline Intellectual Stiffness & 2 & 0.62 & Adaptational Flexibility \\
Subordination & 4 & 0.87 & Dominance \\
Defensiveness & 16 & 0.36 & Openness \\
Passiveness & 22 & 0.86 & Activeness \\
\hline
\end{tabular}

\section{Factor 2. Persistence}

\begin{tabular}{lccl}
\hline Conformism & Item number & Factor load & Nonconformism \\
\hline Submissiveness & 18 & 0.62 & Consistency \\
Low resilience and perseverance & 20 & 0.76 & Resilience and perseverance \\
Timidity & $24 \mathrm{R}$ & & \\
\hline
\end{tabular}

Factor 3. Dominance

\begin{tabular}{lccl}
\hline Conformism & Item number & Factor load & Nonconformism \\
\hline Intolerance & 5 & -0.54 & Tolerance \\
Reliance & 7 & 0.66 & Self-reliance \\
Stereotypicality & 9 & 0.60 & Originality \\
Low self-esteem & 26 & 0,66 & High self-esteem \\
& & & \\
\hline
\end{tabular}

\section{Factor 4. Independence}

\begin{tabular}{lccl}
\hline Conformism & Item number & Factor load & Nonconformism \\
\hline Dependence & 12 & 0.70 & Independence \\
Lack of self-criticism & 25 & 0.75 & Self-criticism \\
\hline
\end{tabular}

Table 8. Conformism - Nonconformism scale factors. 


\section{Factor 1. Eagerness to learn}

\begin{tabular}{lccc}
\hline Algorithmic thinking & Item number & Factor load & Heuristic thinking \\
\hline Low reflectivity & 3 & 0.74 & High reflectivity \\
Learning through reasoning & 8 & 0.68 & Learning through insight \\
Guided Perceptiveness & 13 & 0.37 & Independence of observation \\
Convergent thinking & 14 & 0.59 & Divergent thinking \\
Cognitive passiveness & 21 & 0.68 & Cognitive activity \\
\hline
\end{tabular}

Factor 2. Innovation

\begin{tabular}{lccl}
\hline Algorithmic thinking & Item number & Factor load & Heuristic thinking \\
\hline Lack of artistic aptitude & 10 & 0.67 & Artistic aptitude \\
Imitative imagination & 11 & 0.80 & Creative imagination \\
Constructional skill and aptitude & 17 & 0.65 & Low constructional skill and aptitude \\
\hline
\end{tabular}

\section{Factor 3. Self-Reliance}

\begin{tabular}{lccl}
\hline Algorithmic thinking & Item number & Factor load & Heuristic thinking \\
\hline Copying & 6 & 0.59 & Intellectual Self-reliance \\
Guided learning & $15 \mathrm{R}$ & 0.57 & Independent learning \\
Intellectual stiffness & 19 & -.068 & Intellectual flexibility \\
\hline
\end{tabular}

\section{Factor 4. Verbal creativity}

\begin{tabular}{lccl}
\hline Algorithmic thinking & Item number & Factor load & Heuristic thinking \\
\hline Verbal imitation & 1 & 0.86 & Verbal creativity \\
\hline
\end{tabular}

Table 9. Algorithmic - Heuristic thinking scale factors. 


\subsubsection{Confirmatory data analysis.}

Confirmatory analysis of the CBQ questionnaire has not been carried out in the research to date. To confirm the good fit of the empirical data to the model resulting from the exploratory analysis, confirmatory factor analysis was performed. We present the data for the initial two-factor model, the hierarchical structure and the best fitted model.

\begin{tabular}{llcccc}
\hline Model & Type & $C F I$ & RMSEA & LO90 & $H I 90$ \\
\hline 1 & Two-factor & 0,581 & 0,082 & 0,073 & 0,090 \\
2 & Bifactor & 0,701 & 0,059 & 0,052 & 0,067 \\
3 & Hierarchical & 0,542 & 0,085 & 0,077 & 0,094 \\
\hline
\end{tabular}

Table 10. Due to the fact that no overall model meets the fit criteria, the models for $\mathrm{CN}$ and $\mathrm{AH}$ factors were analyzed separately.

\begin{tabular}{llcccc}
\hline Model & Type & CFI & $\begin{array}{c}\text { RMSE } \\
A\end{array}$ & LO90 & HI90 \\
\hline 1 & Initial & 0,879 & 0,061 & 0,039 & 0,081 \\
2 & Hierarchical & 0,663 & 0,097 & 0,080 & 0,114 \\
3 & Bifactor & 0,918 & 0,053 & 0,027 & 0,075
\end{tabular}

Table 11. Confirmatory analysis models for Conformism - Nonconformism Scale.

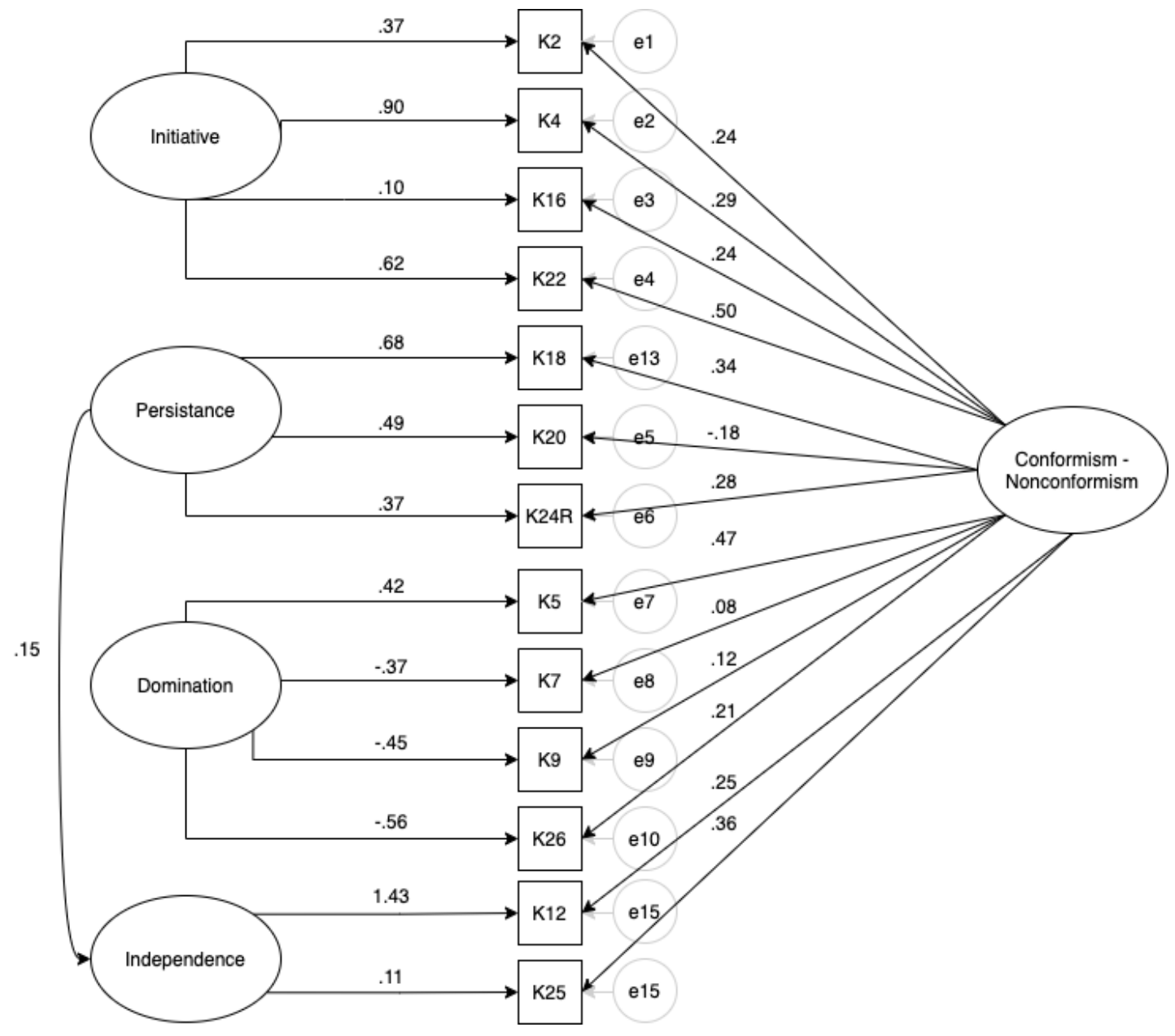


Figure 5. Bifactor model for Conformism-nonconformism scale.

\begin{tabular}{llcccc}
\hline Model & Type & CFI & $\begin{array}{c}\text { RMSE } \\
A\end{array}$ & LO90 & HI90 \\
\hline 1 & Initial & 0,814 & 0,071 & 0,050 & 0,091 \\
2 & Hierarchical & 0,677 & 0,094 & 0,076 & 0,113 \\
3 & Bifactor & 0,923 & 0,051 & 0,020 & 0,076
\end{tabular}

Table 12. Confirmatory analysis models for Algorithmic - Heuristic thinking scale.

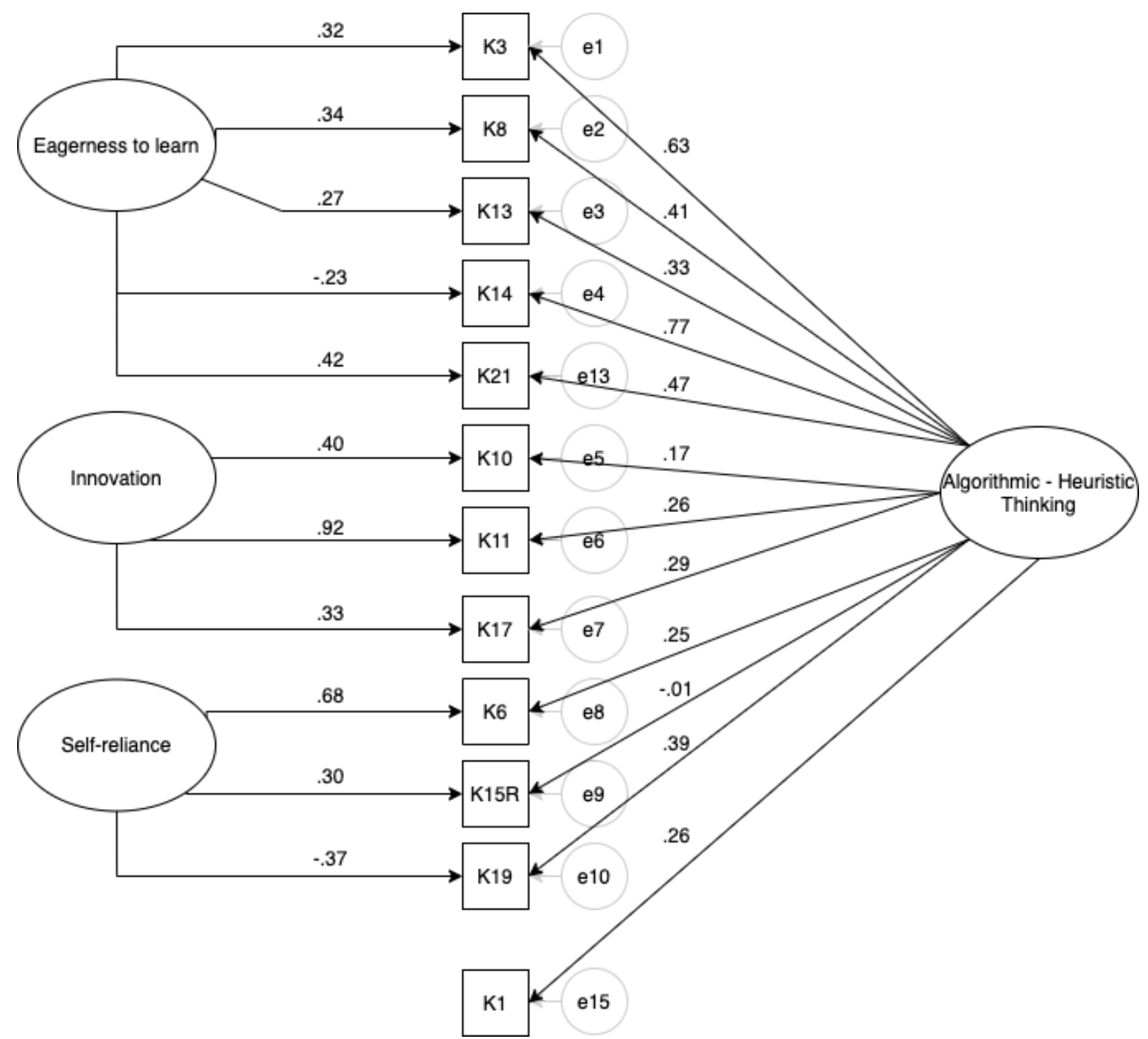

Figure. 6 Bifactor model for Algorithmic - Heuristic thinking scale.

\subsubsection{Validity analysis.}

In order to determine the convergent and discriminant validity, we used the Bochumin Inventory of Personality Determinants of Work (BIP) by R. Hossiep and M. Paschen. There were two main reasons behind using this inventory. Firstly, the authors of the CBQ III used the NEO-FFI by Costa and McCrae to examine the validity, a tool that is based on the Five Factor Model of personality. BIP Inventory also refers to the Five Factor Model, but is additionally oriented to measure personality traits in the vocational context. Secondly, because BIP Inventory consists of a broader range of scales, for instance measuring motivation or social competencies, we took the opportunity to investigate the diversity of personality, motivation 
and soft skill profiles of specialists. The result of the between role and between seniority analysis is described further in the article.

The score on the Algorithmic-Heuristic Thinking (AH) scale was correlated by Bernacka (2016) with the flexibility of cognitive structures measured with the Heuristic Questionnaire (Kwestionariusz Heurystyczności). In our study, in order to test convergent criterion validity, we compared the result from this scale with the results from the BIP Inventory - the Flexibility scale. Although the HA scale measures a cognitive construct, and the BIP Flexibility scale - a personality trait, a statistically significant correlation was observed $(\mathrm{r}=0.31 \mathrm{p}=0.001)$.

In earlier studies (Bernacka 2016), the convergent validity of the Conformism-Nonconformism (CN) scale was examined, with the scales from the NEO-FFI Personality Inventory. Authors have found moderate positive correlations with the scores on the extraversion and conscientiousness scales and a moderate negative correlation with neuroticism. In our study, we used BIP Inventory scales similar in content to the scales used in the previous study - Openness to Contact, Conscientiousness and Emotional Stability scales, respectively. All three scales were expected to correlate positively with CN scale, because the Emotional Stability construct is the opposite to Neuroticism in NEO-FFI. Correlation analysis showed significant and moderately strong correlations between the scores on the SC scale and all three related BIP scales (with $\mathrm{r}=0.56, \mathrm{p}<0.001 \mathrm{for}$ Openness to Contact, $\mathrm{r}=0.29, \mathrm{p}=0.003$ for Conscientiousness and $\mathrm{r}=0.34, \mathrm{p}=0.001$ for Emotional Stability). All interscale correlations are presented in the figure 7 and 8.

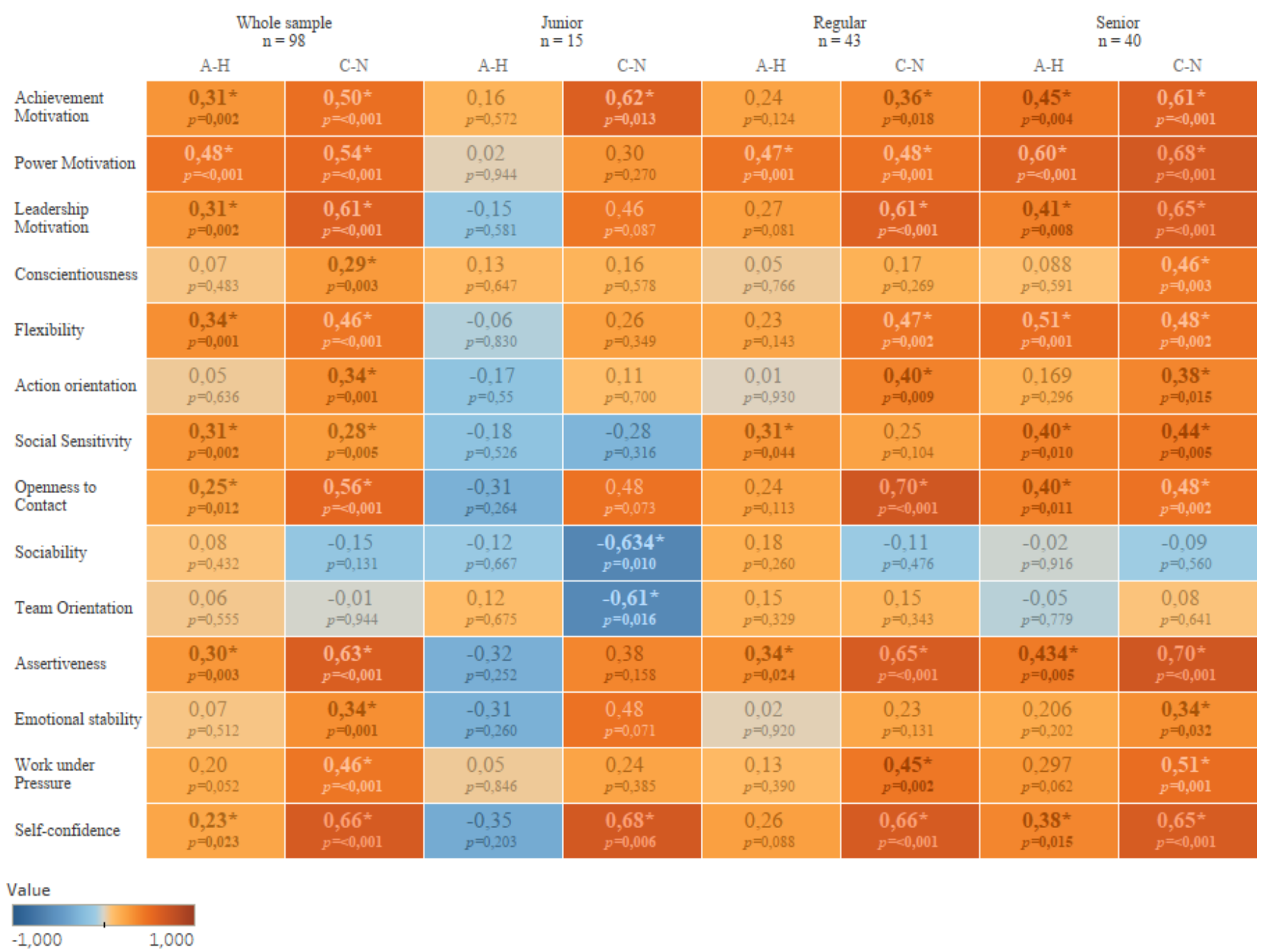

Figure 7. All BIP Inventory scales correlations with CBQ III subscales for the whole sample and subgroups of different seniority levels. * $-\mathrm{p}<0,05$ 


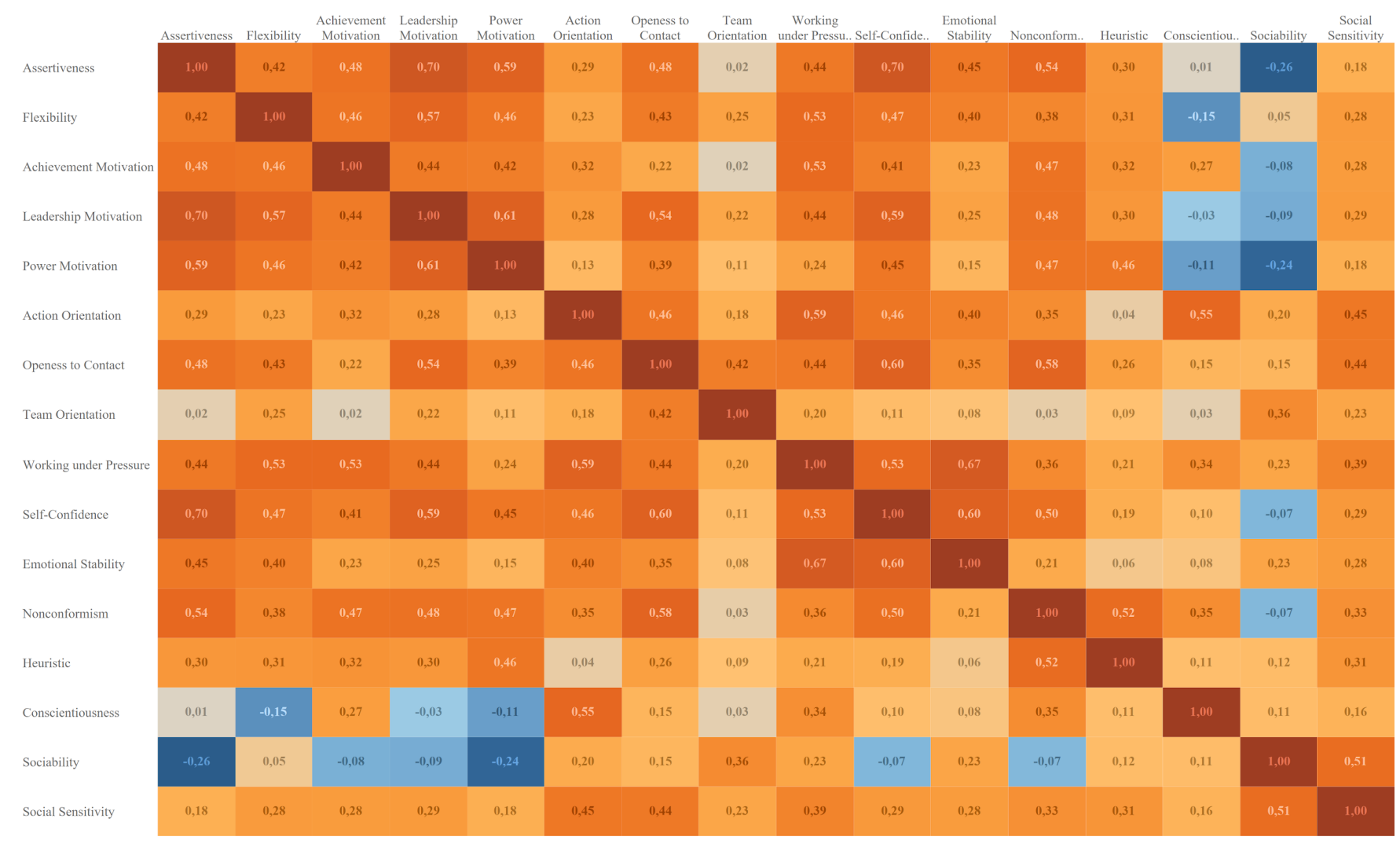

Figure 8. CBQ and BIP scales correlation matrix

\subsubsection{Standardization.}

Standardized scores in the original tool were calculated separately for men and women and for different age groups. In the analyzed group, based on the Mann-Whitney $U$ test, no differences between the genders and age groups were identified. There were also no differences for seniority, therefore standardized results were calculated for the whole group. Detailed data are presented in Table 13. Standardized results are presented in Table 14.

\begin{tabular}{|c|c|c|c|c|c|c|c|c|}
\hline \multirow[t]{2}{*}{ Gender } & \multicolumn{3}{|l|}{ Female } & \multicolumn{3}{|l|}{ Male } & \multirow[t]{2}{*}{$\mathrm{Z}$} & \multirow[t]{2}{*}{$\mathrm{P}$} \\
\hline & Mean rank & Median & IQR & Mean rank & Median & IQR & & \\
\hline $\mathrm{AH}$ & 91,14 & 37 & 9 & 94,96 & 37,50 & 6 & $-0,96$ & 0,335 \\
\hline $\mathrm{CN}$ & 100,71 & 35 & 7 & 84,89 & 34,50 & 8 & $-1,01$ & 0,310 \\
\hline \multirow[t]{2}{*}{ Age } & \multicolumn{3}{|l|}{$21-29$} & \multicolumn{3}{|l|}{$30-41$} & \multirow[t]{2}{*}{ Z } & \multirow[t]{2}{*}{$\mathrm{P}$} \\
\hline & Mean rank & Median & IQR & Mean rank & Median & IQR & & \\
\hline $\mathrm{AH}$ & 51,81 & 37 & 7 & 50,69 & 36 & 10,50 & $-1,08$ & 0,279 \\
\hline $\mathrm{CN}$ & 45,61 & 35 & 8 & 46,97 & 34 & 7,00 & $-0,65$ & 0,516 \\
\hline
\end{tabular}




\begin{tabular}{|c|c|c|c|c|c|c|c|c|c|c|c|}
\hline \multirow[t]{2}{*}{ Seniority } & \multicolumn{3}{|l|}{ Junior } & \multicolumn{3}{|c|}{ Regular } & \multicolumn{3}{|l|}{ Senior } & \multirow[t]{2}{*}{$\mathrm{H}$} & \multirow[t]{2}{*}{$\mathrm{p}$} \\
\hline & $\begin{array}{l}\text { Mean } \\
\text { rank }\end{array}$ & Median & IQR & $\begin{array}{l}\text { Mean } \\
\text { rank }\end{array}$ & Median & IQR & $\begin{array}{l}\text { Mean } \\
\text { rank }\end{array}$ & Median & IQR & & \\
\hline $\mathrm{AH}$ & 97,77 & 37,50 & 8,25 & 91,53 & 37 & 7 & 93,13 & 37 & 9,25 & 0,23 & 0,889 \\
\hline $\mathrm{CN}$ & 81,98 & 34,00 & 7,50 & 89,90 & 35 & 7 & 98,90 & 36 & 8,75 & 2,19 & 0,334 \\
\hline
\end{tabular}

Table 13. CBQ III scores differences according to age, gender and seniority.

\begin{tabular}{|c|c|c|c|c|c|c|c|c|c|c|}
\hline $\begin{array}{l}\text { AH raw } \\
\text { score }\end{array}$ & $\begin{array}{l}\text { CN raw } \\
\text { score }\end{array}$ & $\begin{array}{l}\text { Eagerne } \\
\text { ss to } \\
\text { learn }\end{array}$ & $\begin{array}{l}\text { Innovati } \\
\text { on }\end{array}$ & $\begin{array}{l}\text { Self-reli } \\
\text { ance }\end{array}$ & $\begin{array}{l}\text { Verbal } \\
\text { creativity } \\
\text { item }\end{array}$ & Initiative & $\begin{array}{l}\text { Persist } \\
\text { ence }\end{array}$ & $\begin{array}{l}\text { Dominat } \\
\text { ion }\end{array}$ & $\begin{array}{l}\text { Indepen } \\
\text { dence }\end{array}$ & $\begin{array}{l}\text { Sten } \\
\text { score }\end{array}$ \\
\hline $21-25$ & $19-23$ & $12-16$ & $3-4$ & 6 & & $8-9$ & $5-7$ & 8 & $4-5$ & 1 \\
\hline $26-28$ & 26 & $17-18$ & $5-6$ & 7 & 1 & 10 & 8 & 9 & & 2 \\
\hline $29-30$ & $27-29$ & 19 & 7 & 8 & 2 & $11-12$ & 9 & $10-11$ & 6 & 3 \\
\hline $31-33$ & $30-32$ & 20 & 8 & 9 & & $12-14$ & 10 & 12 & 7 & 4 \\
\hline $34-36$ & $33-35$ & 21 & $9-10$ & 10 & 3 & $15-16$ & 11 & 13 & & 5 \\
\hline $37-39$ & $36-37$ & $22-23$ & 11 & & 4 & 17 & 12 & 14 & 8 & 6 \\
\hline $40-42$ & $38-40$ & 24 & 12 & 11 & & $18-19$ & 13 & 15 & 9 & 7 \\
\hline $43-45$ & $41-43$ & 25 & $13-14$ & 12 & 5 & 20 & 14 & 16 & 10 & 8 \\
\hline $46-47$ & $44-46$ & & 15 & 13 & & & 15 & $17-18$ & & 9 \\
\hline $\begin{array}{l}\text { Above } \\
47\end{array}$ & $\begin{array}{l}\text { Above } \\
47\end{array}$ & & & $14-15$ & & & & $19-20$ & & 10 \\
\hline
\end{tabular}

Table 14. Standardisation of the CBQ scores.

\section{Discussion}

Results of the conducted analyses indicate that the identified factorial structure of the Creative Behaviour Questionnaire III is slightly different than the one described in the original paper by Bernacka (2009). Such inconsistency in the identified factorial structure may be a result of differences between the research samples in both studies as the current one focuses solely on the group employed in the IT industry. We identified 4 factors for Conformism - Nonconformism scale as well as Algorithmic and Heuristic behaviour scale.

We present the psychometric properties of the scale and justify the use of the Creative Behavior Questionnaire invocational context in IT. The psychometric properties, such as reliability and validity are similar and comparable to those presented in the original research.
The adaptation of CBQ III (Bernacka, 2016) was based on exploratory analysis, reliability and validity analysis. The current study enriches the picture of the scale with a confirmatory analysis. Based on this analysis, not only was it possible to confirm the independence of the structure of the C-N and A-H scales, but also showed that both scales consist of independent factors. The obtained results confirm the presence of more than one source of common variance affecting scores. Firstly, some variance is common for all items within the $\mathrm{C}-\mathrm{N}$ and $\mathrm{A}-\mathrm{H}$ subscales. Some variance is explained by the 4 factors that were identified in the exploratory analysis within each of the scales. It is worth noting that these factors have low or moderate reliability, which suggests that the full subscales should be used to calculate and interpret the score. 
We present the standardisation of the scores and norms for the interpretation of CBQ III scores for the population of IT specialists. Seniority, age and sex did not differentiate the obtained results. The only exception is the Verbal creativity subscale, which significantly differentiated seniors from regulars and juniors, so the separate norms for each level of seniority were also presented.

Despite plenty of organisational research done in IT, senior specialist is a poorly researched subject. There are practically no tools adapted for this group on the Polish market. Many authors (Maiden, Jones, Karlsen, Neil, Zachos \& Milne, 2010; Graziotin et al., 2013; Gallivan, 2003) point to the important role of creativity as a key factor of employee success and job satisfaction. This adaptation was intended to introduce the tool which will help in recognizing the talent and will support the career development process. The tool can be used by HR departments as a support for evaluating and managing the career path.

\subsection{Limitations}

Among limiting factors it's important to mention differences in sample sizes, especially the smaller number of junior specialists group representatives. Due to that fact, proper sample size and group balance should be considered in any further research on this topic. However,

\section{References}

Akin, Ö. (1990). Necessary conditions for design expertise and creativity. Design Studies, 11(2), 107-113.

Amabile, T. M. (1983). The social psychology of creativity: A componential conceptualization. Journal of personality and social psychology, 45(2), 357.

Amabile, T. M. (1996). Creatividad e innovación en las organizaciones. Harvard Business School, 305-S11.

Amabile, T. M., \& Pillemer, J. (2012). Perspectives on the social psychology of creativity. The Journal of Creative Behavior, 46(1), 3-15.Ball, Onarheim \& Christensen, 2010;

Bernacka R.E. (2009), KANH III Questionnaire of Creative Behaviour - presentation of the revised version, [w:] S. Popek, R.E. Bernacka, C. Domański, B. Gawda, D. Turska, A. Zawadzka (red.), Psychologia twórczości. Nowe horyzonty, Lublin: Wydawnictwo UMCS, 169-175.

Bernacka R.E. (2016), Constructive and apparent nonconformists at school, [w: C. Pracana (red.), Psychology Applications \& Developments II. Advances in Psychology and Psychological

Campbell JP. Modeling the performance prediction problem in industrial and organizational psychology. In: Dunnette MD, Hough LM, eds. Handbook of industrial and organizational psychology. Palo Alto, CA, US: Consulting Psychologists Press.

Capretz, L. F., \& Ahmed, F. (2010). Making sense of as far as we know it's one of the first attempts to map the personality traits in IT considering both role groups and seniority, as well as using more reliable measures than MBTI.

Another limitation of the current study can be the fact that no exact measure of creativity was used to assess CBQ validity. However this is due to the fact that there are no adequate, verified tools available on polish market. Because of this, next steps should focus on global sample and verification tools should include measures that are popular among creativity researchers.

\subsection{Future considerations}

Current study was first to investigate factor structure of revised Creative Behaviours Questionnaire. We did not find the data fitting the model for the whole scale, however the data was well fitted to the models when analysed for the subscales separately. This implies that items measuring cognitive and behavioural aspects of creativity are distinct. The cognitive creativity of the employee, under certain conditions, might not be expressed in behaviour. Further research could focus on identifying the factors that mediate the relationship between cognitive and behavioural creativity.

software development and personality types. IT professional, 12(1), 6-13.

Capretz, L. F., Varona, D., \& Raza, A. (2015). Influence of personality types in software tasks choices. Computers in Human behavior, 52, 373-378.

Cockburn, A., \& Highsmith, J. (2001). Agile software development, the people factor. Computer, 34(11), 131-133.

Crawford, B., de la Barra, C. L., Soto, R., Misra, S., \& Monfroy, E. (2012, October). Knowledge Management and Creativity Practices in Software Engineering. In KMIS (pp. 277-280).

Cruz, S., da Silva, F. Q., \& Capretz, L. F. (2015). Forty years of research on personality in software engineering: A mapping study. Computers in Human Behavior, 46, 94-113.

de la Barra, C. L., Crawford, B., Soto, R., Misra, S., \& Monfroy, E. (2013, June). Agile software development: it is about knowledge management and creativity. In International Conference on Computational Science and Its Applications (pp. 98-113). Springer, Berlin, Heidelberg.

Díaz-Bossini, J. M., \& Moreno, L. (2014). Accessibility to mobile interfaces for older people. Procedia Computer Science, 27, 57-66.

Ensari, N., Riggio, R. E., Christian, J., \& Carslaw, G. (2011). Who emerges as a leader? Meta-analyses of 
individual differences as predictors of leadership emergence. Personality and Individual Differences, 51(4), 532-536

Foxall, G.R., \& Bhate, S. (1991). Cognitive style, personal involvement and situation as determinants of computer use. Technovation, 11, 183-199.

Gallivan, M. J. (2003). The influence of software developers' creative style on their attitudes to and assimilation of a software process innovation. Information \& Management, 40(5), 443-465.

Graziotin, D., Wang, X., \& Abrahamsson, P. (2013, June). Are happy developers more productive?. In International Conference on Product Focused Software Process Improvement (pp. 50-64). Springer, Berlin, Heidelberg.Hogan \& Judge, 2012

Judge, T. A., Bono, J. E., Ilies, R., \& Gerhardt, M. W. (2002). Personality and leadership: a qualitative and quantitative review. Journal of applied psychology, 87(4), 76

Kanij, T., Merkel, R., \& Grundy, J. (2015, May). An empirical investigation of personality traits of software testers. In 2015 IEEE/ACM 8th International Workshop on Cooperative and Human Aspects of Software Engineering (pp. 1-7). IEEE.Maiden, Jones, Karlsen, Neil, Zachos and Milne, 2010

Kirton, M. (1976). Adaptors and Innovators: A Description and Measure. Journal of Applied Psychology, 61, 622-629.

Kirton, M. J. (1994). A theory of cognitive style. In M. J. Kirton (Ed.), Adaptors and innovators: Styles of creativity and problem-solving (pp. 1-33). London: Routledge.

Kirton, M. J. (1999). Kirton Adaption-Innovation Inventory manual (3rd ed.). Berkhamsted, UK: Occupational Research Center.

Koopmans, L., Bernaards, C. M., Hildebrandt, V. H., De Vet, H. C., \& Van der Beek, A. J. (2014). Construct validity of the individual work performance questionnaire. Journal of occupational and environmental medicine, 56(3), 331-337.

Lemos, J., Alves, C., Duboc, L., \& Rodrigues, G. N. (2012, March). A systematic mapping study on creativity in requirements engineering. In Proceedings of the 27th Annual ACM Symposium on Applied Computing (pp. 1083-1088).

Martínez, L. G., Rodríguez-Díaz, A., Licea, G., \& Castro, J. R. (2010, November). Big five patterns for software engineering roles using an ANFIS learning approach with RAMSET. In Mexican International Conference on Artificial Intelligence (pp. 428-439). Springer, Berlin, Heidelberg.Mich, Anesi and Berry, 2004;
Nęcka E., Grohman M., Słabosz A. (2006), Creativity studies in Poland, [w:] J.C. Kaufman, R.J. Sternberg (red.), International handbook of creativity, Nowy Jork: CUP, 270-306

Nguyen, L., \& Shanks, G. (2009). A framework for understanding creativity in requirements engineering. Information and software technology, 51(3), 655-662.

Popek S. (2000), Kwestionariusz Twórczego Zachowania KANH, Lublin: Wydawnictwo UMCS.

Popek S. (2001), Człowiek jako jednostka twórcza, Lublin: Wydawnictwo UMCS.

Robinson, S. L. (1996). Trust and breach of the psychological contract. Administrative science quarterly, 41(4).

Saha, S. K., Selvi, M., Büyükcan, G., \& Mohymen, M. (2012, May). A systematic review on creativity techniques for requirements engineering. In 2012 International Conference on Informatics, Electronics \& Vision (ICIEV) (pp. 34-39). IEEE.

Schriesheim, C., \& Tsui, A. S. (1980). Development and validation of a short satisfaction instrument for use in survey feedback interventions. Paper presented at the Western Academy of Management meeting.

Shoaib, L., Nadeem, A., \& Akbar, A. (2009, December). An empirical evaluation of the influence of human personality on exploratory software testing. In 2009 IEEE 13th International Multitopic Conference (pp. 1-6). IEEE.

Sutling, K., Mansor, Z., Widyarto, S., Letchmunan, S., \& Arshad, N. H. (2014, September). Agile project manager behavior: The taxonomy. In 2014 8th. Malaysian Software Engineering Conference (MySEC) (pp. 234-239). IEEE.

Williams, L. J., \& Anderson, S. E. (1991). Job satisfaction and organizational commitment as predictors of organizational citizenship and in-role behaviors. Journal of management, 17(3), 601-617.

Winograd, T. (2001). Architectures for context. Human-Computer Interaction, 16(2-4), 401-419.

Wynekoop, J. L., \& Walz, D. B. (2000). Investigating traits of top performing software developers. Information Technology \& People.

Zaccaro, S. J., Kemp, C., \& Bader, P. (2004). Leader traits and attributes. The nature of leadership, 101, 124. 